\title{
Prevention and control of schistosomiasis: a current perspective
}

This article was published in the following Dove Press journal:

Research and Reports in Tropical Medicine

17 October 2014

Number of times this article has been viewed

\author{
Marianette T Inobaya' \\ Remigio M Olveda' \\ Thao NP Chau ${ }^{3}$ \\ David U Olveda ${ }^{2}$ \\ Allen GP Ross ${ }^{2}$ \\ 'Department of Health, Research \\ Institute for Tropical Medicine, \\ Muntinlupa City, Philippines; \\ ${ }^{2}$ Griffith Health Institute, School of \\ Medical Sciences, Gold Coast Campus, \\ Griffith University, Southport, \\ Australia; ${ }^{3}$ Discipline of Public Health, \\ Flinders University, Adelaide, Australia
}

Correspondence: Allen Ross Griffith Health Institute, Griffith University, Gold Coast Campus, Southport, Queensland 4222, Australia Email a.ross@griffith.edu.au

\begin{abstract}
Schistosomiasis is a neglected tropical disease that ranks second only to malaria in terms of human suffering in the tropics and subtropics. Five species are known to infect man and there are currently over 240 million people infected worldwide. The cornerstone of control to date has been mass drug administration with $40 \mathrm{mg} / \mathrm{kg}$ of praziquantel but there are problems with this approach. Human and bovine vaccines are in various stages of development. Integrated control, targeting the life cycle, is the only approach that will lead to sustainability and future elimination.
\end{abstract}

Keywords: schistosomiais, morbidity, treatment and control, mass drug administration

\section{Introduction}

Schistosomiasis is caused by infectious trematode worms of the genus Schistosoma. There are five schistosome species known to infect humans: S. haematobium (identified in 1852), S. japonicum (1904), S. mansoni (1907), S. intercalatum (1934), and S. mekongi (1978). ${ }^{1}$ In 2011, an estimated 243 million people in 78 countries were living in areas of high risk for the disease. ${ }^{2}$ The African region is the most affected, with 42 countries endemic for the infection, followed by the Eastern Mediterranean region with 16 countries affected. Schistosomiasis was also endemic in 10 countries in the region of the Americas, six in the Western Pacific regions, and three in the Southeast Asian region and in Turkey, the only country affected in the European region (Figure 1).

The disability-adjusted life years (DALYs) lost as a result of schistosomiasis was estimated to be 1.7 million. ${ }^{3,4}$ However, in estimating the DALYs, the case definition used for schistosomiasis was limited to infection and associated mortality from schistosomiasis, and excludes mortality from bladder cancer, cirrhosis, or colon cancer that may be related to the infection. Hence, only an average of 0.006 disability weights was used in the estimation. ${ }^{3}$ King re-estimated the DALYs associated with Schistosoma infection using the assumption that all past and present Schistosoma infections are part of the ongoing disease burden of schistosomiasis. Using a disability weight of $2 \%$, the new DALYs estimate was 24-29 million, which was almost 20 times higher than the previous estimate. ${ }^{5}$

Elimation and control of schistosomiasis has been successful in a number of countries including Japan, Tunisia, Puerto Rico, Iran, Mauritius, Venezuela, Morocco, and most of the Caribbean, but it remains a major public health challenge in many other countries. In this current perspective, we discuss the current burden of disease, 


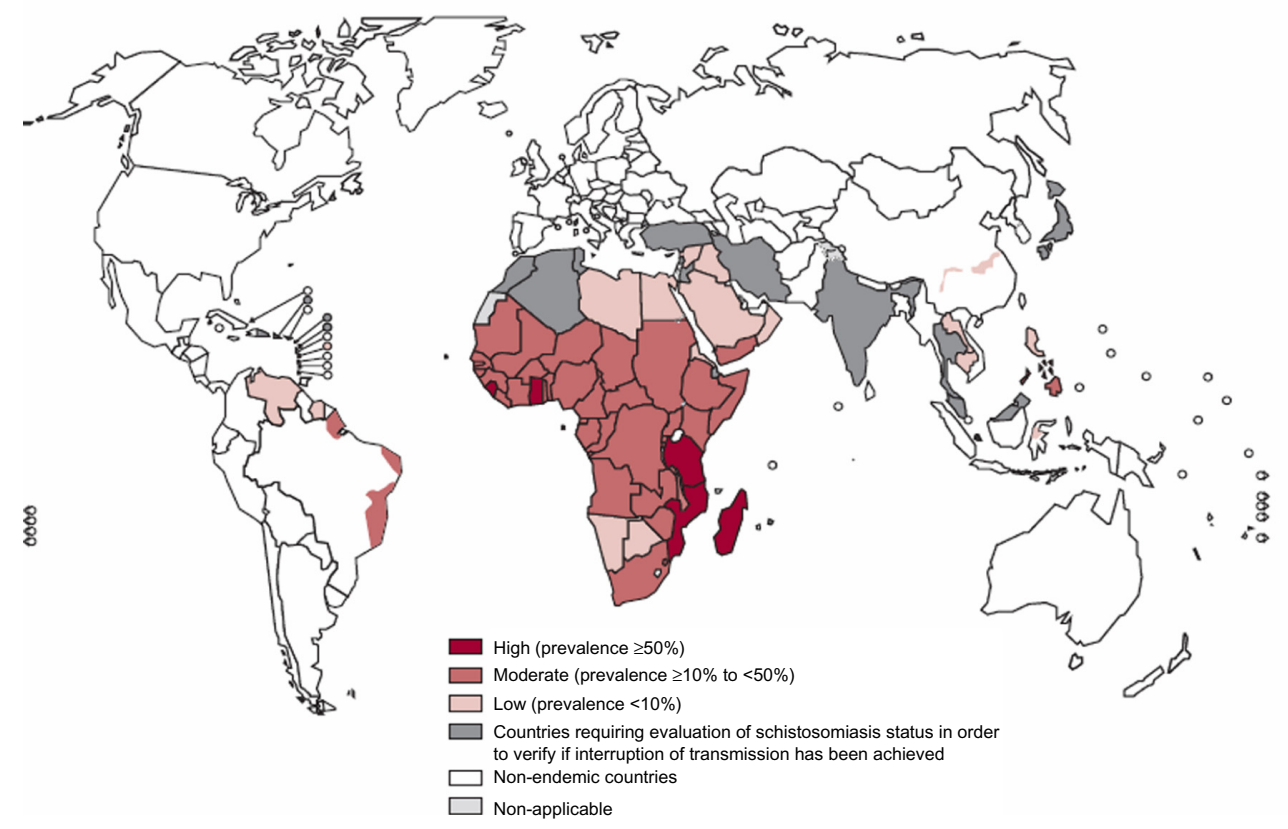

Figure I Worldwide geographical distribution of schistosomiasis in 2010.

Note: Copyright (C) 2013 World Health Organization. Reproduced, with the permission of the publisher, from Schistosomiasis Progress Report (200 I-20I I) and Strategic Plan (2012-2020), Geneva, World Health Organization, 20I3. Available from: http://www.who.int/schistosomiasis/resources/en/. Accessed December 9, 20I3.'

the life cycle, morbidity, treatment, integrated control, and disease prevention.

\section{Life cycle}

Schistosoma eggs are excreted from the human host into a fresh water environment through urine or feces. Once an egg comes in contact with fresh water, it hatches and releases a miracidium, a free-living and ciliated form, which remains infective for 6-12 hours. ${ }^{6}$ The miracidium swims by ciliary movement toward the snail intermediate host and penetrates its soft tissue. The Schistosoma species are transmitted by different fresh water snails that serve as their intermediate hosts: Biomphalaria, Bulinus, and Oncomelania for S. mansoni, S. haematobium, and $S$. japonicum, respectively.

The miracidium that penetrated the snail loses its cilia and develops into a mother sporocyst, which multiplies asexually to produce daughter sporocysts. These migrate to and develop in the hepatic and gonadal tissue of the snail. Within 2-4 weeks, these daughter sporocysts metamorphose into cercariae. ${ }^{6}$ Under the stimulation of light, hundreds of free-swimming, fork-tailed cercariae leave the snail intermediate host. ${ }^{7}$ They swim through the water until they come into contact with human skin or the skin of other mammalian hosts, in the case of S. japonicum. S. japonicum can infect more than 40 mammals that can serve as reservoir hosts. ${ }^{8}$ The cercariae penetrate the skin by mechanical activity and via proteolytic enzymes. ${ }^{9}$ Upon skin penetration, the cercariae lose their tail and become schistosomules which pass through the epidermis and dermis before exiting via the blood or lymphatic vessels. ${ }^{10}$ There seems to be a difference in the way different schistosome species migrate through the skin. Within 2 hours of exposure, more than half of the $S$. japonicum schistosomula are found in the dermis, and as early as this, some are already in the dermal blood vessels. The pace of movement of $S$. mansoni and S. haematobium through the human skin layers is slower than that of $S$. japonicum. It takes about 48 hours for the majority of $S$. mansoni and S. haematobium schistosomula to reach the dermis and 72 hours for these species to be found in the vicinity of the dermal blood vessels. The schistosomules leave the dermis via the venous or lymphatic vessels and migrate to the heart and lungs. ${ }^{11}$ Schistosomules then migrate to the portal or vestibule circulation where they mature into adult worms. Adult S. japonicum, S. mekongi, and S. intercalatum worms stay in the portal and mesenteric vessels while S. haematobium worms live in the vesical plexus. ${ }^{12}$ Mating of the adult worms also occurs in these locations. During mating, the male adult schistosome embraces the female worm into its gynecophoric canal. ${ }^{9}$ Four to 6 weeks after the cercaria has penetrated the human skin, the female adult worm starts producing eggs, except for $S$. haematobium worms, which take about 60-63 days (or 9 weeks) before oviposition takes place. ${ }^{11,13}$ These adult female worms continue producing throughout their lifetime. ${ }^{14}$ The number of eggs produced per day ranges from about 300 eggs for S. mansoni and S. haematobium to as many as 3,000 eggs for $S$. japonicum. ${ }^{12}$ About half the 
number of eggs produced are excreted with feces or urine while the rest stay in the tissues ${ }^{13}$ (Figure 2).

\section{Morbidity}

The clinical manifestation of schistosome infection ranges from a mild dermatitis to chronic infection. Humans exposed to schistosomes for the first time may experience mild prickling sensations with rash at the site of cercarial penetration on the skin within 1 hour of fresh water contact. ${ }^{6,15}$ In those with previous exposures, the cercariae that penetrated the skin elicit a protective response consisting of specific immunoglobulin E antibodies, eosinophils, and macrophages that fight against the schistosomula. The dead schistosomula stay in the skin and become surrounded by

\section{CURRENT CONCEPTS}

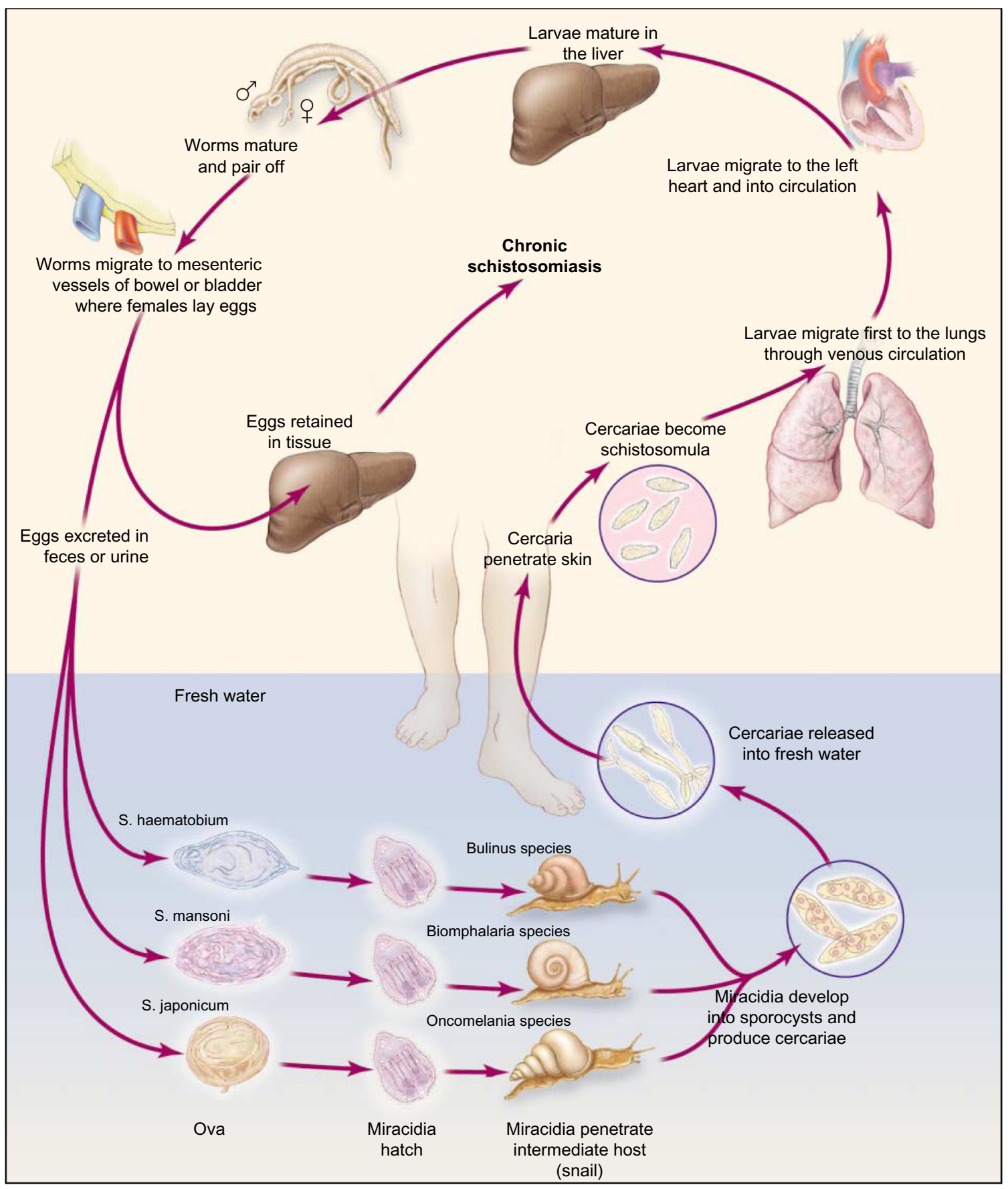

Figure 2 Life cycle of schistosome species.

Note: From The New England Journal of Medicine: Ross AG, Bartley PB, Sleigh AC, et al. Schistosomiasis. 2002;346(16):1212-I220. Copyright @ 2002 Massachusetts Medical Society. Reprinted with permission from Massachusetts Medical Society. ${ }^{17}$ 
edema and massive cellular infiltrates that result in a more severe case of schistosomal dermatitis marked by papules, erythema, vesicles, edema, and pruritus. ${ }^{12}$

Schistosomula that survive the antibody response upon skin penetration will continue on to migrate inside the body via the blood or the lymphatics. Migration of the schistosomula as well as deposition of the eggs produced by adult worms stimulates a hypersensitivity reaction known as Katayama fever. This acute infection may occur within 14-84 days after a primary exposure to contaminated water. ${ }^{9}$ The onset of Katayama fever is sudden, with flu-like symptoms such as fever, fatigue, myalgia, headache, and nonproductive cough. ${ }^{7,9}$ Patients may also have marked peripheral eosinophilia, elevated immunoglobulin E, and patchy pulmonary infiltrates. The infected person may recover suddenly after $2-10$ weeks, but some may worsen and develop more persistent disease characterized by weight loss, dyspnea, diarrhea, diffuse abdominal pain, hepatomegaly, and generalized rash. ${ }^{9}$ S. japonicum can cause Katayama fever in humans with primary infection, as well as in those living in endemic areas including those with previous infections. Cases of Katayama fever caused by $S$. mansoni and $S$. haematobium are less common among people in endemic areas due to underdiagnosis or desensitization at an early age, causing the symptoms to be less severe. ${ }^{7,9}$

Clinical manifestations among chronically infected cases are mainly due to immune reactions against Schistosoma eggs trapped in the tissues during migration. Eggs produce proteolytic enzymes that provoke a reaction in the human host causing eosinophilic inflammation followed by granuloma formation. The granuloma is composed of neutrophils, eosinophils, mononuclear cells, lymphocytes, macrophages, multinucleated giant cells, and fibroblasts. ${ }^{6,7}$ A granuloma can be protective by neutralizing the proteolytic enzymes produced by the eggs. It also forms a physical barrier that prevents egg enzymes and toxins from coming into contact with the tissue. ${ }^{16}$ As the immune response dies down, collagen deposits replace the granuloma. However, a disturbance in this process may lead to excessive collagen deposits, forming fibrotic lesions. ${ }^{6,12}$ The large granulomas and fibrosis produced by the host's immune response against the Schistosoma eggs are the primary cause of morbidity in chronic Schistosoma infection. ${ }^{12}$ The manifestation of the infection is dependent on the individual immune response as well as on the intensity of infection and location of the Schistosoma worms and eggs.,

Urinary schistosomiasis results from S. haematobium eggs deposited in the vesical and ureteral walls that cause granulomatous inflammation. It is characterized by symptoms such as hematuria, dysuria, proteinuria, calcification in the bladder, obstruction of the ureter, renal colic, dark-colored urine, and frequent and painful urination. Obstructive uropathy, renal failure, hydroureter, hydronephrosis, and bladder cancer may develop from chronic infection. . $^{6,76}$

$S$. mansoni and $S$. japonicum are involved in intestinal schistosomiasis. Eggs of these parasites are trapped in the wall and mesenterium of the large intestine and rectum. In a minority of cases, eggs in the small intestines provoke inflammation, hyperplasia, ulceration, microabcess formation, and polyposis. ${ }^{17}$ Symptoms include abdominal pain, diarrhea alternating with constipation, and occult blood in the feces. ${ }^{6,717}$ Infection may lead to bowel obstruction, appendicitis, and gastrointestinal perforation. ${ }^{6}$ In severe cases, colonic or rectal stenosis may result. ${ }^{17}$ Granulomatous inflammation around $S$. mansoni or $S$. japonicum eggs induces presinusoidal inflammation and periportal fibrosis. ${ }^{17}$ These fibrotic streaks converge, forming Symmer's pipe stem fibrosis that may occlude the portal veins, resulting in portal hypertension. ${ }^{6}$ Ascites, hepatosplenomegaly, hypersplenism, varices, and variceal bleeding may occur as a consequence of portal hypertension. ${ }^{17,18}$

There are cases of eggs being deposited in the central nervous system, although the precise mechanism of deposition is unknown. ${ }^{17}$ Tranverse myelitis is the most common manifestation of the presence of S. mansoni and $S$. haematobium in the central nervous system. Symptoms include pain in the lumbosacral area and the lower limbs, paraplegia, pain or loss of sensation, and loss of bladder and bowel sphincter control. ${ }^{6,19}$ S. japonicum, on the other hand, is often associated with cerebral granulomatous lesions causing a syndrome characterized by epilepsy, paralysis, and meningoencephalitis. ${ }^{6}$ Schistosomiasis is also known to affect the pulmonary and genital areas, and childhood infections may lead to growth retardation, anemia, cognitive impairment, and memory deficit. ${ }^{17}$

\section{Treatment}

Of the 78 countries where schistosomiasis is endemic, 52 countries and territories required large-scale treatment for the disease in 2012, comprising treatment for approximately 250 million people. ${ }^{1,20}$ Praziquantel, a pyrazinosoquinolone derivative, is an anthelminthic drug targeting a broad range of parasitic infections, and thus is advocated by the World Health Organization (WHO) for population-based mass chemotherapy. Its anthelminthic activity was discovered in 1972 and it was initially developed for use in animals. 
Subsequently, it has been shown to be effective against all the various schistosome species known to infect humans and against cestodes, and is well tolerated by humans. ${ }^{21}$ Approximately $80 \%$ of the drug is rapidly absorbed from the gastrointestinal tract. ${ }^{13,22}$ It is metabolized by the liver and excreted through the urine and feces. ${ }^{22}$

Multicenter trials conducted by the WHO and Bayer found a single dose of $40 \mathrm{mg} / \mathrm{kg}$ body weight to be effective against $S$. haematobium and S. mansoni, and two doses of $30 \mathrm{mg} / \mathrm{kg}$ body weight for $S$. japonicum, with cure rates of $75 \%-100 \% .^{21}$ Studies of praziquantel against S. mansoni and $S$. haematobium among schoolchildren, at a dosage of $40 \mathrm{mg} / \mathrm{kg}$ body weight, resulted in cure rates of $60.9 \%-88.6 \% \%^{23-26}$ and $39.8 \%-88.9 \%,{ }^{26-31}$ respectively. In children aged $\leq 7$ years, $77.6 \%$ of treatment-naïve children were cured of $S$. mansoni infection, with lower rates among children who had been previously treated with praziquantel..$^{32}$ Multiple doses of praziquantel $40 \mathrm{mg} / \mathrm{kg}$ resulted in cure rates of $41.9 \%$ to as high as $100 \%$ among individuals infected with $S$. mansoni, while the cure rates for $S$. haematobium infection, ie, $53.1 \%-88.0 \%$, did not vary much from that of the single dose. ${ }^{33,34}$ A higher praziquantel dose of $60 \mathrm{mg} / \mathrm{kg}$ body weight against $S$. japonicum in the Philippines did not provide significant additional efficacy in treating Schistosome infection (92.61\% versus $97.03 \%) .{ }^{35}$

The benefits of praziquantel are its high efficacy, ease of administration, relative safety, and mild to moderate side effects, including nausea, dizziness, rash, pruritus, headache, drowsiness, and abdominal pain. ${ }^{36,37}$ However, treatment with praziquantel may sometimes fail, and this may be due to possible drug resistance. In the S. mansoni outbreak in Northern Senegal, treatment of infected cases with praziquantel resulted in very low cure rates of 18\%-36\%. In Egypt, 1.6\% of S. mansoni cases remain uncured even after three doses of praziquantel, with the third dose at $60 \mathrm{mg} / \mathrm{kg}$. Experiments done in Italy, Egypt, and the UK revealed that laboratorymaintained S. mansoni isolates showed diverse sensitivities to praziquantel. There were also case reports of travellers who were infected during their stay in endemic areas and were treated with praziquantel, but resulted in treatment failure. ${ }^{38}$ Another possible cause of treatment failure, apart from resistance, is the inefficacy of praziquantel in treating earlier stages of schistosomes. Poor compliance with the drug may also result in untreated and uncured cases.

Oxamniquine is an aminoethyltetrahydroquinolone derivative that was first described in the late 1960s. It is known to be effective only against $S$. mansoni, particularly the invasive stages and adult worms, with male worms more sensitive to the drug than female worms. ${ }^{37,39}$ Like praziquantel, oxamniquine is rapidly absorbed, reaching its maximal plasma concentration in 1-4 hours after intake. Metabolism of the drug is by oxidation, and excretion is mostly through the urine. ${ }^{39}$ High therapeutic efficacy may be achieved by administering the drug at a dose of $15-60 \mathrm{mg} / \mathrm{kg}$ body weight over 2-3 days. ${ }^{20}$ A study in Brazil among S. mansoniinfected individuals has shown oxamniquine to be similar to praziquantel in terms of safety and efficacy by cure rate, with the outcome of infection detected by stool examination. However, praziquantel was more effective when measured with quantitative oogram by biopsy of rectal mucosa. ${ }^{37}$

An alternative group of drugs being considered are derivatives of artemisinin, an isolated compound of Artemisia annua L. Compositae. ${ }^{40}$ The artemisinin derivatives, artesunate and artemether, are known antimalarial drugs but were discovered as possible antischistosomal drugs in the 1980 s, with early studies focusing on S. japonicum. ${ }^{39}$ Unlike praziquantel and oxamniquine, which are known to be most effective against adult worms, artemisinin is effective against the younger stages of the schistosome while the adult stage is less susceptible to this drug. ${ }^{23,39}$ Artemether is more effective against female adult worms than male ones, with studies showing that female $S$. mansoni cause degenerative changes in the parenchyma and reproductive system of mice. ${ }^{40} \mathrm{~A}$ randomized controlled trial was conducted in the People's Republic of China to assess the efficacy of combining artemether with praziquantel, and the results showed that artemether did not improve the efficacy of praziquantel in the treatment of S. japonicum infection. ${ }^{41}$ Although artesunate has been explored for its antischistosomal properties, clinical trials in patients with $S$. haematobium have shown that artesunate alone does not offer any therapeutic advantage over praziquantel. ${ }^{27,42}$

Combination of artemisinin derivatives with other compounds, ie, artemisinin-based combination therapies, has yielded varied results, with very small sample sizes showing higher cure rates. Cure rates in S. haematobium infection using artesunate with sulfadoxine/sulfalene and pyrimethamine or with amodiaquine, varied from $44 \%$ to $100 \% .^{29,42}$ Artesunate with sulfadoxine/sulfalene and pyrimethamine to treat $S$. mansoni infection have resulted in an even wider range of cure rates (from $14 \%$ to $100 \%$ ). Artemether with lumefantine to treat Plasmodium falciparum and S. mansoni coinfection gave a $100 \%$ cure rate. ${ }^{43}$ Although these studies have shown varied effects of the artemisinin-based combination therapies on schistosome infection, they are candidate treatment alternatives that should be explored further. 
In addition to antischistosomal drugs, corticosteroids are also being administered as adjuvant therapy in cases of neuroschistosomiasis ${ }^{36,44}$ and their is a case report of their use in urinary schistosomiasis. ${ }^{45}$ Corticosteroids reduce the immune response, hence prevent excessive granulomatous inflammation and tissue damage. ${ }^{44,46,47}$ Clinical trials are required to test the effect of corticosteroids in the treatment of schistosomiasis. However, case reports indicate a beneficial effect of their use in combination with praziquantel and other antischistosomal drugs. ${ }^{45-48}$

\section{Prevention}

The basic means of preventing Schistosoma infection is avoiding contact with fresh water infested with Schistosome parasites. Swimming, wading, or any other aquatic activities in these bodies of water exposes the skin to possible penetration by the cercariae. In cases when there is brief accidental contact with infected water, vigorous towel drying is advised to help prevent the cercariae from penetrating the skin. In using water from these fresh water sources for drinking or bathing, water must be brought to the boil for at least 1 minute to kill the parasite that may be present in the water. ${ }^{49}$ Allowing the water to stand for 24 hours or more before using it may also help in preventing infection. Fine-mesh filters may also be used to filter the cercariae possibly contained in the water. Insect repellants such as DEET (N,N-Diethyl-meta-toluamide) may be applied topically to prevent cercariae from penetrating the skin, but this is not a very reliable measure. ${ }^{50}$

Contact with infected water cannot always be avoided, especially by people in endemic areas whose occupation (eg, fishing, rice farming) or day-to-day activity exposes them to these waters. The WHO has recommended preventive chemotherapy as a strategy for morbidity control that will help lessen the occurrence, extent, and severity of the consequences of infection. ${ }^{1}$ Although preventive chemotherapy cannot prevent reinfection, it may cause a reduction in the production of eggs, which in turn prevents the morbidity caused by deposition of the egg in the human tissue. ${ }^{51}$ Preventive chemotherapy is targeted toward school-aged children in endemic areas because they are known to have a high risk of infection. In areas where the prevalence of infection is at least $10 \%$, preventive treatment should also be given to those who are at high risk of infection because of their occupation, such as fishermen, farmers, and irrigation workers, as well as women who may be exposed to infected waters when performing their domestic chores. Pregnant and lactating women in these areas should also be included in preventive chemotherapy campaigns because they are considered at high risk of developing morbidity due to schistosomiasis infection. ${ }^{1}$

\section{Control}

One of the earliest efforts in the control of schistosomiasis was in the 1920s, when Egypt implemented the first mass drug administration campaigns in adults and children using intravenous tartar emetic. This was followed by implementation of a national program that included chemotherapy and/or snail control as strategies for controlling the disease. Discovery of safe drugs, like niridazole, metrifonate, oxamniquine, and praziquantel for treating human infection refocused the attention of control strategies on chemotherapy. In 2001, the World Health Assembly drafted resolution 54.19 that endorsed chemotherapy as the main strategy for control of schistosomiasis through mass drug administration. This resolution set a target of 75\%-100\% regular chemotherapy coverage for school-aged children (aged 5-14 years) at risk of morbidity by $2010 .{ }^{1}$ But, as noted during the 65 th World Health Assembly held in May 2012, this target was not achieved. ${ }^{20}$ In 2010, over 108 million school-aged children required treatment, and at least 21 million were given treatment $(19 \%)$ far below the target stated in the resolution. This was based on reports from $28(55 \%)$ of 51 countries where preventive chemotherapy against schistosomiasis should have been applied. ${ }^{52}$

Mass drug administration aims to lessen morbidity and mortality due to the infection and prevent new infection by limiting transmission through reduction of the overall prevalence in the population. ${ }^{53}$ The assumption is that mass drug administration would also lead to reduction in excretion of schistosome eggs, contamination of the environment, and infection of the snail population, which in turn would lead to less source of infection for humans. However, for those who do not comply or are not covered by mass drug administration, such as school-aged children who are not enrolled in school, they may still spread the infection. Likewise, the unavoidable contacts of humans to hot spots of transmission leads to the failure of mass drug administration to stop transmission in high-risk communities. ${ }^{54}$

Before implementing a large-scale mass drug administration program, epidemiological assessment of the community should be done to determine the prevalence and presence of ongoing transmission of infection. The prevalence is the basis for the recommended strategy for preventive chemotherapy (Table 1). In high-risk communities, where the prevalence 
Table I Treatment strategy recommended by the World Health Organization for schistosomiasis

\begin{tabular}{|c|c|c|c|}
\hline Category & Prevalence in school-aged children & Action to be taken & \\
\hline $\begin{array}{l}\text { High-risk } \\
\text { community }\end{array}$ & $\begin{array}{l}\geq 50 \% \text { by parasitological methods } \\
\text { (intestinal and urinary schistosomiasis) } \\
\text { or } \\
\geq 30 \% \text { by questionnaire for visible } \\
\text { hematuria (urinary schistosomiasis) }\end{array}$ & $\begin{array}{l}\text { Treat all school-aged children (enrolled } \\
\text { and not enrolled) once a year }\end{array}$ & $\begin{array}{l}\text { Also treat adults considered to } \\
\text { be at risk (from special groups }{ }^{\mathrm{a}} \\
\text { to entire communities living in } \\
\text { endemic areas) }\end{array}$ \\
\hline $\begin{array}{l}\text { Moderate-risk } \\
\text { community }\end{array}$ & $\begin{array}{l}\geq 10 \% \text { but }<50 \% \text { by parasitological } \\
\text { methods (intestinal and urinary } \\
\text { schistosomiasis) } \\
\text { or } \\
<30 \% \text { by questionnaire for visible } \\
\text { hematuria (urinary schistosomiasis) }\end{array}$ & $\begin{array}{l}\text { Treat all school-aged children (enrolled } \\
\text { and not enrolled) once every } 2 \text { years }\end{array}$ & $\begin{array}{l}\text { Also treat adults considered to be } \\
\text { at risk (from special groups }{ }^{\mathrm{a}} \text { only) }\end{array}$ \\
\hline $\begin{array}{l}\text { Low-risk } \\
\text { community }\end{array}$ & $\begin{array}{l}<\mathrm{I} 0 \% \text { by parasitological methods } \\
\text { (intestinal and urinary schistosomiasis) }\end{array}$ & $\begin{array}{l}\text { Treat all school-aged children (enrolled } \\
\text { and not enrolled) twice during their } \\
\text { primary schooling age (eg, once on } \\
\text { entry and once on exit) }\end{array}$ & $\begin{array}{l}\text { Praziquantel should be available } \\
\text { in dispensaries and clinics for } \\
\text { treatment of suspected cases }\end{array}$ \\
\hline
\end{tabular}

of infection is at least $50 \%$ as detected by parasitological methods or urinary schistosomiasis has a prevalence of $30 \%$ or higher based on history of hematuria, all school-aged children as well as adults considered to be at risk are eligible for preventive treatment and should be treated at least once a year. Adults deemed at high-risk are those who are occupationally exposed to infected water, such as fishermen, farmers, irrigation workers, and women performing domestic chores. Entire communities living in endemic areas are also considered eligible. Communities where prevalence determined by parasitological methods is at least $10 \%$ but not less than $50 \%$ or where urinary schistosomiasis detected by history of hematuria has a prevalence of less than $30 \%$ are classified as having moderate risk. In these areas, school-aged children as well as those in the special risk groups (mentioned above) should be given preventive treatment every 2 years. Only school-aged children are treated in areas classified as low-risk communities (prevalence $<10 \%$ by parasitological methods). Treatment should be given only twice during the primary school years. The drug should be made available in community clinics or dispensaries for treatment of suspected cases. ${ }^{55}$

Mass drug administration has been implemented in several countries as part of national schistosomiasis control programs. It has been included in the control programs of countries like Uganda, Sierra Leone, Burkina Faso, Brazil, Mali, Niger, the People's Republic of China, and the Philippines. ${ }^{53,56-60}$ Praziquantel, the drug of choice in implementing mass drug administration, is safe and inexpensive, making this intervention relatively low cost with a rapid and significant impact on disease prevalence and intensity ${ }^{61}$ However, even with the low cost of the drug, given the large number of people at risk of infection, the overall cost of implementing mass drug administration is still very difficult for affected countries to sustain. Most of the mass drug administration programs are donor-driven, and when the financial support stops, the treatment campaign ends. Such was the case in Mali in the 1980s, where the prevalence was successfully reduced, but when the external funding support stopped, the treatment cycles ceased, and the prevalence quickly returned to the baseline level. This increase in prevalence back to preintervention values may happen within 18-24 months after treatment is stopped. ${ }^{62}$ Compliance with treatment has also been a problem in many countries, including the Philippines, wherein considerable efforts were made to disseminate information about mass drug administration but compliance was still below 50\%.62,63 Another concern that may arise with repeated administration of praziquantel is the possible development of resistance or tolerance to the drug. ${ }^{53}$

Given the limitations of mass drug administration in the control of schistosomiasis, it is often implemented in combination with other strategies, such as snail control. This strategy corresponds to the other vital component of schistosomiasis control, ie, intervention targeting the snail intermediate host. Mollusciciding or application of chemical compounds called molluscicides is a common method for elimination of snails. ${ }^{64}$ It was introduced in Egypt in the 1940s where copper sulfate was the chemical agent used. A more efficient drug, sodium pentachlorophenate, was also 
first used in Egypt in $1955 .{ }^{65}$ There were four compounds for mollusciciding listed in the report of a WHO expert committee in 1972. These compounds were Yurimin, sodium pentachlorophenate, N-tritylmorpholine, and niclosamide. ${ }^{66}$ At present, niclosamide is the only WHO recommended molluscicide. ${ }^{64}$ It comes in different formulations, such as $70 \%$ wettable powder and $25 \%$ emulsifiable concentrate, as well as in granules and sand and gelatin forms, and has been used with some success. ${ }^{66}$ A meta-analysis of studies in the People's Republic of China on the comparative molluscicidal efficacy of two formulations of niclosamide showed that use of $50 \%$ niclosamide ethanolamine salt wettable powder resulted in $88 \%$ snail mortality while $4 \%$ niclosamide ethanolamine powder caused $93 \%$ mortality in the snail population. The less than $100 \%$ mortality in the snail population after a single application of niclosamide indicates that only a small proportion of snails is able to survive the molluscicide. Therefore, for mollusciciding to be effective in eliminating snails, dosing must be done at least twice a year. ${ }^{64}$ The need to repeat treatment makes this strategy time-consuming and less cost-effective, especially for large areas. ${ }^{67}$ The most economic and effective approach to controlling the snail population would be to use focal and seasonal application of molluscicide, targeting implementation based on the transmission cycle. ${ }^{68}$ Aside from the cost, other concerns regarding the use of molluscicides is their toxic effect on macro-organisms and micro-organisms and environmental pollution. ${ }^{69,70}$ Other means of controlling snails are by environmental methods, such as burying their habitats, flooding the snails with water up to several meters in depth, and digging ditches or water drainage tunnels. ${ }^{71}$

Elimination of schistosomiasis takes more than just mass drug administration and snail control to achieve. World Health Assembly resolution 54.19 also urged promotion of health education, access to safe water, and sanitation in all member nations. ${ }^{1}$ Health education may lead to behavioral changes like avoidance of contact with schistosome-infested waters and contamination of the environment with feces. For behavioral change to be feasible, alternatives must be given and complemented with provision of sanitary water and toilet facilities. ${ }^{72}$ In Ghana, to discourage school-aged children from going to the local river, a water recreation area was built as an alternative swimming area, and this resulted in a significant decrease in incidence of the disease. ${ }^{73,74}$ In the People's Republic of China, fecal matter containers were provided to boats to prevent disposal of human feces in the waters. ${ }^{70}$

These strategies are often combined to form a comprehensive integrated control program. In Egypt, the combination of chemotherapy, snail control, provision of potable water, and improved sanitation has resulted in less morbidity, prevalence, and severity of infection. ${ }^{1}$ A 3 -year implementation of a combination of mass drug administration, an information and education campaign, provision of a safe water supply, and construction of latrines in Burkina Faso, Niger, and Mali led to decreased prevalence. ${ }^{60}$ One successful example of combining different strategies to form an integrated control program was the National Schistosomiasis Control Programme implemented in the People's Republic of China in 2004. This program aimed to reduce the rate of infection in humans to $<5 \%$ by 2008 and to $<1 \%$ by 2015 . The strategies used include mass treatment with praziquantel and intensified health education. One of the strategies is to reduce transmission from humans to snails by supplying tap water and building lavatories, public latrines, and marsh gas pools, and providing boats with containers for fecal matter to avoid contamination of water with feces. In the control program implemented in the People's Republic of China, cattle were replaced with small farm machines and grazing of cattle on grassland was prohibited in an effort to eliminate cattle as a source of infection. This program was successful in reducing the rate of infection by $75 \%-90 \%$ after 30 months. Aside from the reduction in infection rate, the program also had a significant impact on transmission. After two to three transmission seasons, $S$. japonicum-infected snails decreased by $93 \%-100 \%$, the sampled grassland with infected snails was reduced by $95 \%-100 \%$, and the infectivity of the Poyang Lake declined by $97 \%-100 \%{ }^{70}$

Given that schistosomiasis is a public health problem in countries where other neglected tropical diseases are also prevalent, control programs for some of these diseases can be integrated to maximize the use of resources in curtailing these infections. One example is integration of control for schistosomiasis with that for soil-transmitted helminthic infection. The populations at risk for these infections are overlapping and risk factors like poor hygiene, lack of safe water, and inadequate sanitation are common to both infections. The strategies recommended by the WHO for control of soil-transmitted helminths and for schistosomiasis are the same, starting with morbidity control. The drug therapy recommended for schistosomiasis can be safely coadministered with drugs recommended for soil-transmitted helminth infections, such as albendazole and mebendazole. ${ }^{55}$ Thus, integrating the control program of these infections can be cost-effective.

\section{Conclusion}

Although the methods being deployed in schistosomiasis control programs have had considerable success in reducing the burden of infection, these methods have limitations. Mass 
Table 2 Schistosome candidate vaccines in advance stages of development

\begin{tabular}{|c|c|c|c|c|c|}
\hline $\begin{array}{l}\text { Vaccine } \\
\text { candidate }\end{array}$ & $\begin{array}{l}\text { Location in } \\
\text { adult worm }\end{array}$ & Identity & $\begin{array}{l}\text { Production } \\
\text { platform }\end{array}$ & Organization & Stage of development \\
\hline Sml4 & $\begin{array}{l}\text { Whole body } \\
\text { cytosolic }\end{array}$ & $\begin{array}{l}\text { Fatty acid binding } \\
\text { protein }\end{array}$ & $\begin{array}{l}\text { Recombinant } \\
\text { protein }\end{array}$ & $\begin{array}{l}\text { Fundacao } \\
\text { Oswaldo Cruz }\end{array}$ & Phase I clinical testing \\
\hline Sm-TSP-2 & $\begin{array}{l}\text { Tegument apical } \\
\text { membrane }\end{array}$ & $\begin{array}{l}\text { Tetraspanin integral } \\
\text { membrane protein }\end{array}$ & $\begin{array}{l}\text { Recombinant } \\
\text { protein }\end{array}$ & Sabin PDP & $\begin{array}{l}\text { Cyclic guanosine } \\
\text { monophosphate manufacture } \\
\text { Undergoing toxicology testing }\end{array}$ \\
\hline Smp80 (Calpain) & $\begin{array}{l}\text { Associated with } \\
\text { tegument inner } \\
\text { membrane }\end{array}$ & $\begin{array}{l}\text { Calpain - neutral } \\
\text { cysteine protease }\end{array}$ & DNA & Texas Tech & Preclinical \\
\hline Sh28GST (Bhilvax) & Whole body & $\begin{array}{l}\text { Glutathione } \\
\text { S-transferase }\end{array}$ & $\begin{array}{l}\text { Recombinant } \\
\text { protein }\end{array}$ & $\begin{array}{l}\text { Institut Pasteur } \\
\text { Lille }\end{array}$ & Phase II clinical trial \\
\hline
\end{tabular}

Note: Copyright (C) 2008 American Society for Microbiology. Adapted from McManus DP, Loukas A. Current status of vaccines for schistosomiasis. Clin Microbiol Rev. 2008;2I(I):225-242. ${ }^{75}$ Copyright (C) 2013. Adapted from Beaumer CM, Gillespie PM, Hotez PJ, Bottazi ME. New vaccines for neglected parasitic diseases and dengue. Transl Res. 2013;162(3):144-155. ${ }^{77}$

drug administration, which is the main strategy for control, does not prevent reinfection, and infection rates tend to return to baseline values within 24 months after chemotherapy. ${ }^{75}$ Hence, this strategy needs to be repeated with a frequency depending on the endemic risk level of the community. Therefore, the search for integrated control measures with a more lasting effect must continue.

Numerous candidate vaccines have been explored, and some of these are already in the advanced stages of development (Table 2). Sm14 kDa is a fatty acid binding protein of $S$. mansoni ${ }^{76}$ and is already in Phase I clinical trials as a candidate vaccine. ${ }^{77}$ Smp 80 calpain, or calcium-activated neutral cysteine protease, is associated with the tegument inner membrane. ${ }^{75}$ It was manufactured as a DNA vaccine and has shown good protection in animal models. ${ }^{76} \mathrm{Sm}$-TSP-2, a member of the tetraspanin family of proteins, is undergoing toxicology testing. The vaccine candidate in the most advanced stage of development is Sh28GST (Bhilvax). It is already in Phase II clinical testing. ${ }^{77}$ However, it will still take decades or longer before these vaccines can be commercially available. While the world waits, integrated control initiatives must continue.

\section{Acknowledgments}

The authors would like to thank the UBS-Optimus Foundation, the National Health and Medical Research Council, Australia, and the National Institutes for Health, Bethesda, MD, USA (RMO award 1P50AI098481-01) and the International Development Research Centre of Canada for providing financial support for schistosomiasis research in the Philippines.

\section{Disclosure}

The authors report no conflicts of interest in this work. Ethical clearance was not required for this review.

\section{References}

1. World Health Organization. Schistosomiasis Progress Report (2001-2011) and Strategic Plan (2012-2020). Geneva, Switzerland: World Health Organization Press; 2013. Available from: http://www. who.int/schistosomiasis/resources/en/. Accessed December 9, 2013.

2. Barry MA, Simon GG, Mistry N, Hotez PJ. Global trends in neglected tropical disease control and elimination: impact on child health. Arch Dis Child. 2013;98(8):635-641.

3. Mathers CD, Ezzati M, Lopez AD. Measuring the burden of neglected tropical diseases: the global burden of disease framework. PLoS Negl Trop Dis. 2007;7:1(2):e114.

4. World Health Organization. The global burden of disease: 2004 update. Geneva, Switzerland: World Health Organization Press; 2008. Available from: http://www.who.int/healthinfo/global_burden_disease/2004_ report_update/en/. Accessed July 16, 2014.

5. King $\mathrm{CH}$. Parasites and poverty: the case of schistosomiasis. Acta Trop. 2010;113(2):95-104.

6. Gryseels B, Strickland GM. Schistosomiasis. In: Magill AJ, Hill DR, Solomon T, Ryan ET, editors. Hunter's Tropical Medicine and Emerging Infectious Disease. 9th ed. Philadelphia, PA, USA: Elsevier; 2013.

7. Gryseels B. Schistosomiasis. Infect Dis Clin North Am. 2012;26(2): 383-397.

8. Gordon CA, Acosta LP, Gray DJ, et al. High prevalence of Schistosoma japonicum infection in carabao from Samar Province, the Philippines: implications for transmission control. PLoS Negl Trop Dis. 2012;6(9):e1778.

9. Ross AG, Vickers D, Olds GR, Shah SM, McManus DP. Katayama syndrome. Lancet Infect Dis. 2007;7(3):218-224.

10. Curwen RS, Wilson RA. Invasion of skin by schistosome cercariae: some neglected facts. Trends Parasitol. 2003;19(2):63-66.

11. He YX, Salafsky B, Ramaswany K. Comparison of skin invasion among three major species of Schistosoma. Trends Parasitol. 2005;21(5):201-203.

12. Maguire JH. Trematodes (schistosomes and other flukes). In: Mandell GL, Bennett JE, Dolin R, editors. Mandell, Douglas and Bennett's Principles and Practices of Infectious Diseases. 7th ed. Philadelphia, PA, USA: Elsevier; 2010.

13. Holick DS, Kaul TL. Schistosomiasis. Urol Nurs. 2013;33(4): 163-170.

14. Bustinduy AL, King CH. Schistosomiasis. In: Farrar J, Hotez PJ, Junghanss T, Kang G, Lalloo D, White NJ, editors. Manson's Tropical Disease. 23rd ed. Philadelphia, PA, USA: Elsevier; 2014.

15. Boros DL. Immunopathology of Schistosoma mansoni infection. Clin Microbiol Rev. 1989;2(3):250-269.

16. Hams E, Aviello G, Fallon PG. The schistosoma granuloma: friend or foe? Front Immunol. 2013;4:89. 
17. Ross AG, Bartley PB, Sleigh AC, et al. Schistosomiasis. N Engl J Med. 2002;346(16):1212-1220.

18. Li Y, Chen D, Ross AG, et al. Severe hepatosplenic schistosomiasis: clinicopathologic study of 102 cases undergoing splenectomy. Hum Pathol. 2011;42(1):111-119.

19. Nascimento-Carvalho CM, Moreno-Carvalho OA. Neuroschistosomiasis due to Schistosoma mansoni: a review of pathogenesis, clinical syndromes and diagnostic approaches. Rev Inst Med Trop Sao Paulo. 2005;47(4):179-184.

20. World Health Organization. Schistosomiasis: number of people treated in 2012. Wkly Epidemiol Rec. 2014;89(4):21-28.

21. Reich MR, Govindaraj R, Dumbaugh K, et al. In: Reich MR, editor. International Strategies for Tropical Disease Treatment: Experiences with Praziquantel. Geneva, Switzerland: World Health Organization; 1998.

22. Chai JY. Praziquantel treatment in trematode and cestode infections: an update. Infect Chemother. 2013;45(1):32-43.

23. Obonyo CO, Muok EM, Mwinzi PN. Efficacy of artesunate with sulfalene plus pyrimethamine versus praziquantel for treatment of Schistosoma mansoni in Kenyan children: an open-label randomized controlled trial. Lancet Infect Dis. 2010;10(9):603-611.

24. Erko B, Degarege A, Tadesse K, Mathiwos A, Legesse M. Efficacy and side effects of praziquantel treatment of Schistosomiasis mansoni in Shesha Kekele Elementary School, Wondo Genet, Southern Ethiopia. Asian Pac J Trop Biomed. 2012;2(3):235-239.

25. Reta B, Erko B. Efficacy and side effects of praziquantel in the treatment for Schistosoma mansoni infection in school children in Senbete Town, northeastern Ethiopia. Trop Med Int Health. 2013;18(11):1338-1343.

26. Coulibaly JT, N'Gbesso YK, Knopp S, Keiser J, N'Goran EK, Utzinger J. Efficacy and safety of praziquantel in preschool-aged children in an area co-endemic for Schistosoma mansoni and S. haematobium. PLoS Negl Trop Dis. 2012;6(12):e1917.

27. Borrmann S, Szlezak N, Faucher JF, et al. Artesunate and praziquantel for the treatment of Schistosoma haematobium infections: a double-blind, randomized, placebo-controlled study. J Infect Dis. 2001;184(10):1363-1366.

28. Keiser J, N'Guessan NA, Adoubryn KD, et al. Efficacy and safety of mefloquine, artesunate, mefloquine-artesunate and praziquantel against Schistosoma haematobium: randomized, exploratory open-label trial. Clin Infect Dis. 2010;50(9):1205-1213.

29. Sissoko MS, Dabo A, Traore H, et al. Efficacy of artesunate + sulfamethoxypyrazine/pyrimethamine versus praziquantel in the treatment of Schistosoma haematobium in children. PLoS One. 2009;4(10):e6732.

30. Tchuente LA, Shaw DJ, Polla L, Cioli D, Vercruysse J. Efficacy of praziquantel against Schistosoma haematobium infection in children. Am J Trop Med Hyg. 2004;71(6):778-782.

31. Guidi A, Andolina C, Makame Ame S, Albonico M, Cioli D, Juma Haji H. Praziquantel efficacy and long-term appraisal of schistosomiasis control in Pemba Island. Trop Med Int Health. 2010;15(5):614-618.

32. Sousa-Fugueiredo JC, Betson M, Atuhaire A, et al. Performance and safety of praziquantel for treatment of intestinal schistosomiasis in infants and preschool children. PLoS Negl Trop Dis. 2012;6(10):e1864.

33. Garba A, Lamine MS, Barkire N, et al. Efficacy and safety of two closely spaced doses of praziqauntel against Schistosoma haematobium and S. mansoni and re-infection patterns in school-aged children in Niger. Acta Trop. 2013;128(2):334-344.

34. Tchuem Tchuente LA, Momo SC, Stothard JR, Rollinson D. Efficacy of praziquantel and reinfection patterns in single and mixed infection foci for intestinal and urogenital schistosomiasis in Cameroon. Acta Trop. 2013;128(2):275-283.

35. Olliare PL, Vaillant MT, Belizario VJ, et al. A multicentre randomized controlled trial of the efficacy and safety of single-dose praziquantel at 40 $\mathrm{mg} / \mathrm{kg}$ vs $60 \mathrm{mg} / \mathrm{kg}$ for treating intestinal schistosomiasis in the Philippines, Mauritania, Tanzania and Brazil. PLos Negl Trop Dis. 2011;5(6):e1165.
36. Gray DJ, Ross AG, Li YS, McManus DP. Diagnosis and management of schistosomiasis. BMJ. 2011;342:d2651.

37. Ferrari ML, Coelho PM, Antunes CM, Tavares CA, da Cunha AS. Efficacy of oxamniquine and praziquantel in the treatment of Schistosoma mansoni infection: a controlled trial. Bull World Health Organ. 2003;81(3):190-196.

38. Doenhoff MJ, Cioli D, Utzinger J. Praziquantel: mechanisms of action, resistance and new derivatives for schistosomiasis. Curr Opin Infect Dis. 2008;21(6):659-667.

39. Utzinger J, N'Goran EK, N'Dri A, Xiao S, Tanner M. Oral artemether for prevention of Schistosoma mansoni infection: randomized controlled trial. Lancet. 2000;355(9212):1320-1325.

40. Araujo N, Kohn A, Katz N. Activity of the artemether in experimental schisosomiasis mansoni. Mem Inst Oswaldo Cruz. 1991;86 Suppl 2: $185-188$.

41. Hou XY, McManus DP, Gray DJ, et al. A randomized double-blind placebo-controlled trial of safety and efficacy of combined praziquantel and artemether treatment for acute Schistosomiasis japonica in China. Bull World Health Organ. 2008;86(10):788-795.

42. Utzinger J, Tanner M, Keiser J. ACTs for schistosomiasis: do they act? Lancet Infect Dis. 2010;10(9):579-581.

43. Abay SM, Tilahun M, Fikrie N, Habtewold A. Plasmodium falciparum and Schistosoma mansoni coinfection and the side benefit of artemether-lumefantrine in malaria patients. J Infect Dev Ctries. 2013;7(6):468-474.

44. Ross AG, McManus DP, Farrar J, Huntsman RJ, Gray DJ, Li YS. Neuroschistosomiasis. J Neurol. 2012;259(1):22-32.

45. Miller MJ, Reid EC. Steroid therapy in chronic urinary schistosomiasis (bilharziasis). Can Med Assoc J. 1967;97(11):594-599.

46. Badr HI, Shaker AA, Mansour MA, et al. Schistosomal myeloradiculopathy due to Schistosoma mansoni: report on 17 cases from an endemic area. Ann Indian Acad Neurol. 2011;14(2):107-110.

47. Fowler R, Lee C, Keystone JS. The role of corticosteroids in the treatment of cerebral schistosomiasis caused by Schistosoma mansoni: case report and discussion. Am J Trop Med Hyg. 1999;61(1):47-50.

48. Lambertucci JR, Voieta I, Silveira Idos S. Cerebral schistososomiasis mansoni. Rev Soc Bras Med Trop. 2008;41(6):693-694.

49. Centers for Disease Control and Prevention. Parasites - schistosamiasis. Available from http://www.cdc.gov/parasites/schistosomiasis/. Accessed January 25, 2014.

50. Montgomery S. Infectious diseases related to travel: schistosomiasis. In: CDC Health Information for International Travel. Available from http://wwwnc.cdc.gov/travel/yellowbook/2014/chapter-3-infectiousdisease-related-to-travel/schistosomiasis. Accessed April 15, 2014.

51. Stothard JR, Figueiredo JC, Navaratnam AM. Advocacy, policies and practicalities of preventive chemotherapy campaigns for African children with schistosomiasis. Expert Rev Anti Infect Ther. 2013:11(7): 733-752.

52. World Health Organization. Schistosomiasis: number of people treated in 2010. Wkly Epidemiol Rec. 2012;87(4):37-44.

53. Humphries D, Nguyen S, Boakye D, Wilson M, Capello M. The promise and pitfalls of mass drug administration to control infections. Curr Opin Infect Dis. 2012;25(5):584-589.

54. King CH. Toward the elimination of schistosomiasis. N Engl J Med. 2009;360(2):106-109.

55. World Health Organization. Preventive chemotherapy in human helminthiasis coordinated use of antihelmintic drugs in control interventions: a manual for health professionals and programme managers. Geneva, Switzerland: World Health Organization; 2006. Available from: http://whqlibdoc.who.int/publications/2006/9241547103_eng.pdf. Accessed July 16, 2014

56. Hodges MH, Dada N, Warmsley A, et al. Mass drug administration significantly reduces Schistosoma mansoni and hookworm in school children in the national control program in Sierra Leone. BMC Infect Dis. 2012;12:16. 
57. Koukounari A, Gabrielli AF, Toure S, et al. Schistosoma haematobium infection and morbidity before and after large-scale administration of praziquantel in Burkina Faso. J Infect Dis. 2007;196(5):659-669.

58. Sarvel AK, Oliveira AA, Silva AR, Lima AC, Katz N. Evaluation of a 25-year program for the control of schistosomiasis mansoni in an endemic are in Brazil. PLoS Negl Trop Dis. 2011;5(3):e990.

59. Sesay S, Paye J, Bah MS, et al. Schistosoma mansoni infection after three years of mass drug administration in Sierra Leone. Parasit Vectors. 2014;7:14

60. Garba A, Toure S, Dembele R, et al. Present and future schistosomiasis control activities with support from Schistosomiasis Control Initiative in West Africa. Parasitology. 2009;136(13):1731-1737.

61. Fenwick A, Webster JP. Schistosomiasis: challenges for control, treatment and drug resistance. Curr Opin Infect Dis. 2006;19(6): 5775-5782.

62. Gray DJ, McManus DP, Li Y, Williams GM, Berqquist R, Ross AG. Schistosomiasis elimination: lessons from the past guide the future. Lancet Infect Dis. 2010;10(10):733-736.

63. Tallo VL, Carabin H, Alday PP, Balolong E Jr, Olveda RM, McGarvey ST. Is mass treatment the appropriate schistosomiasis elimination strategy? Bull World Health Organ. 2008;86(10):765-771.

64. Yang GJ, Li W, Sun LP, et al. Molluscicidal efficacies of different formulations of niclosamide: result of meta-analysis of Chinese literature. Parasit Vectors. 2010;3:84.

65. Barbosa FS, Coimbra CE Jr. Alternative approaches in schistosomiasis control. Mem Inst Oswaldo Cruz. 1992;87 Suppl 4:215-220.

66. McCullough FS, Gayral P, Duncan J, Christie JD. Molluscicides in schistosomiasis control. Bull World Health Organ. 1980;58(5):681-689.

67. Yang GJ, Sun LP, Hong QB. Optimizing molluscicide treatment strategies in different control stages of schistosomiasis in the People's Republic of China. Parasit Vectors. 2012;5:260.

68. Madsen H. Ecological studies on the intermediate host snails and the relevance to schistosomiasis control. Mem Inst Oswaldo Cruz. 1992; 87 Suppl 4:249-253.

69. Mazigo HD, Nuhawa F, Kinung'hi SM, et al. Epidemiology and control of human schistosomiasis in Tanzania. Parasit Vectors. 2012;5:274.
70. Wang LD, Chen HG, Guo JG, et al. A strategy to control transmission of Schistosoma japonicum in China. $N$ Engl J Med. 2009;360(2): 121-128.

71. Sleigh A, Li X, Jackson S, Huang K. Eradication of schistosomiasis in Guangxi, China. Part 1: Setting, strategies, operations, and outcomes, 1953-1992. Bull World Health Organ. 1998;76(4):361-372.

72. Colley DG, Bustunduy AL, Secor WE, King CH. Human schistostomiasis. Lancet. 2014;383(9936):2253-2264.

73. Kosinski KC, Adjei MN, Bosompen KM, et al. Effective control of Schistosoma haematobium infection in a Ghanaian community following installation of a water recreation area. PLoS Negl Trop Dis. 2012;6(7):e1709.

74. World Health Organization. Helminth Control in School-Age Children: A Guide for Managers of Control Programmes. 2nd ed. Geneva, Switzerland: World Health Organization; 2011. Available from: http://whqlibdoc.who.int/publications/2011/9789241548267_eng.pdf. Accessed July 16, 2014

75. McManus DP, Loukas A. Current status of vaccines for schistosomiasis Clin Microbiol Rev. 2008;21(1):225-242.

76. Bethony JM, Cole RN, Guo X, et al. Vaccines to combat the neglected diseases. Immunol Rev. 2011;239(1):237-270.

77. Beaumer CM, Gillespie PM, Hotez PJ, Bottazi ME. New vaccines for neglected parasitic diseases and dengue. Transl Res. 2013;162(3): $144-155$.

78. World Health Organization. Model List of Essential Medicines. Geneva, Switzerland: World Health Organization; 2011. Available from: http://whqlibdoc.who.int/hq/2011/a95053_eng.pdf?ua=1. Accessed February 15, 2014.

79. World Health Organization. Expert Committee on the Control of Schistosomiasis. Prevention and Control of Schistosomiasis and Soil-Transmitted Helminthiasis: Report of a Who Expert Committee. 2nd ed. Geneva, Switzerland: World Health Organization; 2002.
Research and Reports in Tropical Medicine

\section{Publish your work in this journal}

Research and Reports in Tropical Medicine is an international, peerreviewed, open access journal publishing original research, case reports, editorials, reviews and commentaries on all areas of tropical medicine, including: Diseases and medicine in tropical regions; Entomology; Epidemiology; Health economics issues; Infectious disease; Laboratory

\section{Dovepress}

science and new technology in tropical medicine; Parasitology; Public health medicine/health care policy in tropical regions; and Microbiology. The manuscript management system is completely online and includes a very quick and fair peer-review system. Visit http://www.dovepress. com/testimonials.php to read real quotes from published authors. 